\title{
Adult Partner Preference and Sexual Behavior of Male Rats Affected by Perinatal Endocrine Manipulations
}

\author{
T. Brand, ${ }^{*}$ J. Kroonen, ${ }^{*}$ J. Mos, $\dagger$ and A. K. Slob* \\ *Department of Endocrinology and Reproduction, Faculty of Medicine and Health Sciences, \\ Erasmus University, P.O. Box 1738, 3000 DR Rotterdam, The Netherlands; and \\ $\dagger$ Department of Pharmacology, Duphar B.V., P.O. Box 900, 1380 DA Weesp, \\ The Netherlands
}

\begin{abstract}
Intact adult male rats, in which aromatization of testosterone to estradiol was prevented pre- and/or neonatally by ATD (1,4,6-androstatriene-3,17-dione), were repeatedly tested for partner preference behavior (choice: estrous female vs active male). In consecutive tests increasing preference scores for the female were found. Neonatal ATD males showed significantly lower preference scores for an estrous female than controls or prenatal ATD males. Prenatal ATD caused preference scores only slightly lower than those of controls. Ejaculation frequencies were markedly reduced or even absent in neonatal ATD males. Prenatal ATD treatment only had no or a moderately lowering effect on ejaculation frequency. Lordosis behavior of adult intact males was more facilitated following neonatal ATD treatment than following prenatal ATD treatment. In a number of tests the serotonergic drug 8-OH-DPAT was injected prior to testing for sexual partner preference and copulatory behavior. DPAT significantly increased preference for an estrous female in all groups of males when interaction was possible, but had no effect when sexual interaction was prevented by wire mesh. DPAT was able to increase the number of ejaculators in nonejaculating groups (i.e., perinatally ATD-treated males). "Premature ejaculations," i.e., ejaculations with the first intromission, were frequently observed with DPAT treatment in all groups of males. In conclusion, the availability of neonatal estrogen (derived from testosterone) organizes, at least partially, the preference for an estrous female normally shown by adult male rats. The lack of neonatal estrogen causes males to be less masculinized, both in partner preference behavior and ejaculatory behavior, and less defeminized in lordosis behavior. Treatment with a scrotonin agonist (8-OH-DPAT) compensates, at least partially, the perinatal ATD effects on adult partner preference behavior and on ejaculatory behavior. (c) 1991 Academic Press, Inc.
\end{abstract}

It has been shown that the estradiol $\left(\mathrm{E}_{2}\right)$ metabolite of testosterone ( $\left.T\right)$ is essential during a critical perinatal period for masculinization and defeminization of sexual behavior in the male rat (e.g., Baum, 1979). Neonatal administration to male rats of ATD (1,4,6-androstatriene-3,17dione), which blocks the conversion of $T$ to $E_{2}$, increased in adulthood the animals' ability to display lordosis behavior either with or without 
exogenous estradiol $\left(E_{2}\right)$ and progesterone $(P)$ (McEwen, Lieberburg, Chaptal, and Krey, 1977; Davis, Chaptal, and McEwen, 1979; Vreeburg, van der Vaart, and van der Schoot, 1977). Prenatal exposure to ATD also enhanced lordosis behavior in castrated male rats, treated with estradiol and progesterone in adulthood (Clemens and Gladue, 1978; Whalen and Olsen, 1981; Whalen, Gladue, and Olsen, 1986).

Adult mounting behavior was unaffected in prenatally ATD treated males, castrated on Day 35 and subsequently treated with TP (Whalen and Olsen, 1981), as well as in neonatally ATD-treated gonadally intact male rats (Vreeburg et al., 1977; Davis et al., 1979). Ejaculatory capacity was blocked by neonatal administration of ADT (androst-4-ene-3,6,17trione), a compound related to ATD, also blocking the conversion of $\mathrm{T}$ to $E_{2}$, in male rats that were castrated at birth and injected with TP for 5 days (Booth, 1978). In these male rats penile development or the occurrence of intromissions was not affected.

Adult partner preference behavior organization has received less attention (e.g., Adkins-Regan, 1988). We have recently reported that this behavior is affected by neonatal castration (Brand and Slob, 1991). It was found that neonatally castrated and oil- or DHTP-treated male rats showed a significantly lower preference for an estrous female (vs a sexually active male) than control males when tested in adulthood for partner preference behavior under testosterone substitution. This suggests that $\mathrm{T}$, through its estradiol metabolite, may play a role in the programming of this behavior.

The present experiments were carried out to study sexual partner preference behavior of adult intact male rats which were exposed to ATD before and shortly after birth. This approach was chosen because it is known that ATD interferes selectively with the aromatization of endogenous testosterone (Kaplan and McGinnis, 1989), but not with the normal somatic development of the internal and external genitalia (Vreeburg et al., 1977). The latter development is mediated through DHT, the $5 \alpha$ reduced metabolite of $T$. Thus, somatically normal male rats with a possibly differentially programmed CNS were studied.

The effects of 8-hydroxy-2-(di-n-propylamino)tetralin (8-OH-DPAT), a serotonergic drug with sexual behavior stimulating properties in male rats (e.g., Ahlenius, Larsson, Svensson, Hjorth, Carlsson, Lindberg, Wickström, Sanchez, Arvidsson, Hacksell, and Nilsson, 1981), were also studied. The effects of perinatal ATD treatment on "defeminization" were investigated in adult males, with and without progesterone, when paired with a sexually active male.

\section{GENERAL METHODS}

\section{Animals}

Experimental animals were Wistar albino rats; stimulus animals were F1 hybrids of two inbred Wistar strains $(\mathrm{R} \times \mathrm{U})$. They were housed two 
to four to a cage with food and water available ad lib and kept in a 14 hr light-10 hr dark cycle (lights on: 5:30 PM to 7:30 AM). Temperature in the animal room ranged from 22 to $24^{\circ} \mathrm{C}$.

\section{Treatments}

Female rats were always time mated. Prenatal treatment of the offspring consisted of ATD, propylene glycol (solvent), or nothing. In experiment 1, ATD was given to pregnant females $(n=4)$ in a 19-cm-long Silastic implant (inner diameter $1.5 \mathrm{~mm}$; outer diameter $2.1 \mathrm{~mm}$ ), placed $\mathrm{sc}$ in the back on Day 11 of pregnancy through parturition. For implantation and removal of the Silastic tube the mothers were lightly anesthetized with ether. Other females $(n=8)$ did not receive an implant. In experiment 2, eight pregnant rats were injected with ATD $(5 \mathrm{mg} / 0.1 \mathrm{ml} ; n=$ 8 ) and four with solvent (propylene glycol, $0.1 \mathrm{ml} / \mathrm{day} ; n=4$ ) from Days 10 to 22 of pregnancy.

Within $9 \mathrm{hr}$ after birth small Silastic implants (inner diameter $1.5 \mathrm{~mm}$; outer diameter $2.1 \mathrm{~mm}$; length $5 \mathrm{~mm}$ ) were placed sc in the back of the newborn male and female pups under ice anesthesia. The implants contained ATD or were left empty (one treatment per litter). The implants were removed when the pups were 10 days (Experiment 1) or 21 days of age (Experiment 2).

Pups were weaned at 21 days of age and housed two to four to a cage of same sex and treatment. They were left undisturbed until the time of behavioral testing, which started at the age of 11 weeks. Most behavioral tests were carried out without any adult treatment, but some tests (see under Method for each experiment) were conducted after an injection with the serotonergic drug 8-OH-DPAT, a $5 \mathrm{HT}_{1 \mathrm{a}}$ receptor agonist, 30 min prior to testing. This drug was dissolved in saline at a concentration of 0.1 or $0.2 \mathrm{mg} / \mathrm{ml}$. The animals were sc injected with a volume of 2 $\mathrm{ml} / \mathrm{kg}$; i.e., they received dosages of 0.2 or $0.4 \mathrm{mg} / \mathrm{kg}$.

Ovariectomized stimulus females were brought into behavioral estrus by injecting $30 \mu \mathrm{g}$ estradiol benzoate (EB) $24-48 \mathrm{hr}$ followed by $2.5 \mathrm{mg}$ progesterone (P) 3 to $4 \mathrm{hr}$ prior to testing. These hormones were dissolved in olive oil.

\section{Behavioral Testing}

Three-compartment partner preference test. A test box made of gray perspex with a transparent front was used (Slob, de Klerk, and Brand, 1987) which had three compartments $(60 \times 30 \times 40 \mathrm{~cm}$ each) with a small opening $(13 \times 12 \mathrm{~cm})$ in both partitions near the front window. These openings could be closed by a sliding door. Stimulus animals could be put in the left and right compartments. These incentives, an estrous female and a sexually active male, wore either a leather harness which was attached with a stainless-steel string to the rear of the compartment or no harness and were placed behind a wire mesh separation halfway 
down the lateral compartment. Tethered animals had a limited action radius. They were adapted to the tethering device during $1 \mathrm{hr}$ in the week before testing. The experimental animal could only see, smell, and hear the incentives when physical interaction was prevented by wire mesh.

Behavioral tests lasted $15 \mathrm{~min}$. Before testing all three animals (one experimental, two incentives) were put in the box, one in each compartment, with the sliding doors closed, for 15-20 min of adaptation. At the beginning of the test the sliding doors were removed and the experimental animal could freely move around and interact with the stimulus animals or sit before the wire mesh separation. Time spent in each compartment was recorded. To quantify partner preference, a preference score was calculated for each test by subtracting the time spent in the compartment containing the sexually active male from time spent near the estrous female (method adopted from Edwards and Pfeifle, 1983). Thus, a positive score indicates preference for the estrous female; a negative score indicates preference for the sexually active male. In the tests in which interaction was possible, the sexual behaviors with the incentives also were scored. Data on ejaculation frequencies and number of intromissions prior to the first ejaculation are presented.

Pair test with estrous female. In these tests, lasting $15 \mathrm{~min}$, semicircular cages measuring $62 \times 40 \times 36 \mathrm{~cm}$ were used. Before the test the experimental male was put in the cage for a 5 -min adaptation period. At the beginning of the test an estrous female was put in the cage. Various behaviors were scored. For this report number of ejaculations and number of intromissions prior to the first ejaculation were analyzed.

Pair test with sexually active male. For these tests, carried out also in semicircular cages, sexually active males were used. After a 5-min adaptation period of the stud males, the experimental males were put in the boxes. The lordosis responses of the experimental male to the mounting of the stud male were recorded. The test lasted until the experimental male had received 10 mounts or, at the longest, $10 \mathrm{~min}$. Since many males were not very attractive and did not receive 10 mounts, we have included in the analyses the lordosis quotients of those experimental males that reccived threc or more mounts by the stud male.

\section{Hormone Assay}

Testosterone concentrations were estimated in serum by radioimmunoassay, without chromatography, using the prevailing method in our laboratory (e.g., Baum, Brand, Ooms, Vreeburg, and Slob, 1988). The interassay and intraassay coefficients of variation were 13.4 and $5.6 \%$, respectively.

\section{Statistics}

Most partner preference data were analyzed using one- or two-way ANOVA (Perlman, 1986). For further analysis the least significant dif- 
ference (LSD) procedure (Kirk, 1968) was used. For analyzing the number of animals displaying a certain type of behavior $\chi^{2}$ analyses were employed.

\section{EXPERIMENT 1}

\section{Method}

In this experiment four groups of males were formed: (1) control $(n=$ 20; out of five litters); (2) prenatal ATD (pre-ATD; $n=6$; two litters); pre- and neonatal ATD (preneo-ATD; $n=12$; two litters); (4) neonatal ATD (neo-ATD; $n=10$; three litters).

In adulthood, these gonadally intact male rats were tested for partner preference behavior at the ages of $11,13,24$, and 25 weeks. Incentives were tethered in tests 1,2 , and 4 and freely moving behind wire mesh in test 3.

Four pair tests for sexual behavior with an estrous female (S1-S4) were carried out at 12,20,21, and 30 weeks of age. In tests S2 and S3 the effects of 8-OH-DPAT $(0.2 \mathrm{mg} / \mathrm{kg} \mathrm{sc} 30 \mathrm{~min}$ prior to testing $)$ were assessed in a cross-over design. For the sake of clarity, all saline data are presented as test S2 and the DPAT data as test S3.

Lordosis behavior of the intact males was studied at the age of 18 weeks in two tests using a sexually active male (L1, without progesterone (P); 1 day later (L2), after $0.5 \mathrm{mg} \mathrm{P} \mathrm{4-7} \mathrm{hr} \mathrm{prior} \mathrm{to} \mathrm{testing).}$

Blood was collected under light ether anesthesia from the orbital plexus at 14.5 weeks of age.

\section{Results}

Partner preferences. Mean partner preference scores are shown in Fig. 1. The data of tests 1,2 , and 4 , with tethered incentives, were analyzed separately from those of test 3 , with incentives behind wire mesh.

In tests 1,2 , and 4 there was a significant group difference $(F(3 /$ $44)=41.50 ; P<0.0005)$, a significant effect of tests $(F(2 / 88)=99.41$; $P<0.0005)$ and a significant Groups $\times$ Tests interaction $(F(6 / 880)=$ $2.92 ; P=0.012)$. Further analysis of this interaction $(\operatorname{LSD}(5 \%)=145.1$ $\mathrm{sec})$ revealed gradually increasing preference scores for the estrous female. In tests 1 and 2 preneo- and neo-ATD males had preference scores significantly lower than those of pre-ATD and control males; the last two groups did not differ. Most of the control (16-19 of 20) and pre-ATD males (5-6 of 6) preferred the estrous female, whereas the majority of the preneo-ATD males (10-11 of 12) and the neo-ATD males (7-8 of 10) preferred the sexually active male. In test 4 virtually all males preferred the estrous female, although the ATD-treated groups had scores significantly lower than those of the controls. Moreover, the preneo-ATD males scored significantly lower than the pre-ATD males, but did not differ from the neo-ATD males.

One-way ANOVA of test 3 revealed an overall group difference 


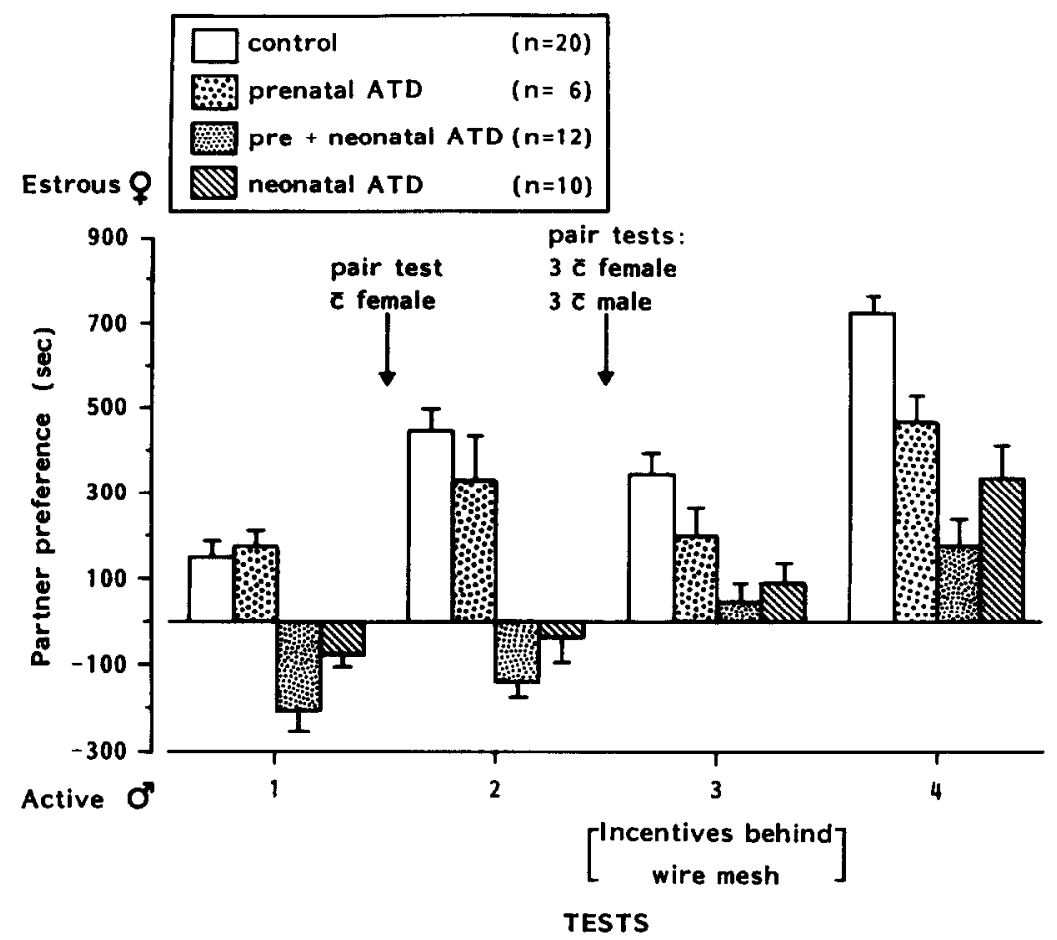

FiG. 1. Mean ( \pm SEM) preference (seconds) for an estrous female over a sexually active male of intact adult male rats after perinatal ATD or control treatment. They were tested four times $(15 \mathrm{~min} /$ test $)$ for partner preference behavior in a three-compartment box. To calculate a preference score, time spent with the sexually active male was subtracted from time spent with the estrous female. A positive score indicates preference for the female; a negative score: preference for the male. In tests 1,2 and 4 sexual interaction with tethered incentives was possible; in test 3 sexual interaction was prevented by wire mesh. Between tests 1 and 2 the males were pair tested with an estrous female (left arrow). Between tests 2 and 3 six pair tests were carried out, three with an estrous female and three with a sexually active male (right arrow).

$(F(3 / 44)=5.38 ; P=0.003)$. Further analysis $(\operatorname{LSD}(5 \%)=117.0 \mathrm{sec})$ showed that all ATD-treated males had preference scores lower than those of controls. The preneo-ATD males showed lower preference for the estrous female than the pre-ATD males. As in test 4, the neo- and preneoATD males did not differ.

Sexual behavior with female during partner preference testing. Sexual behavior during partner preference tests 2 and 4 is depicted in Fig. 2. It seems clear from the figure that neonatal ATD treatment as such (alone or in combination with prenatal ATD) reduced the number of males ejaculating. Hence all males receiving ATD neonatally, i.e., neo- and preneo-ATD combined, were taken together forming group 1 and all males not receiving ATD neonatally, i.e., control and pre-ATD combined, were taken together to form group 2 . In preference tests $2\left(\chi^{2}=25.93\right.$, 

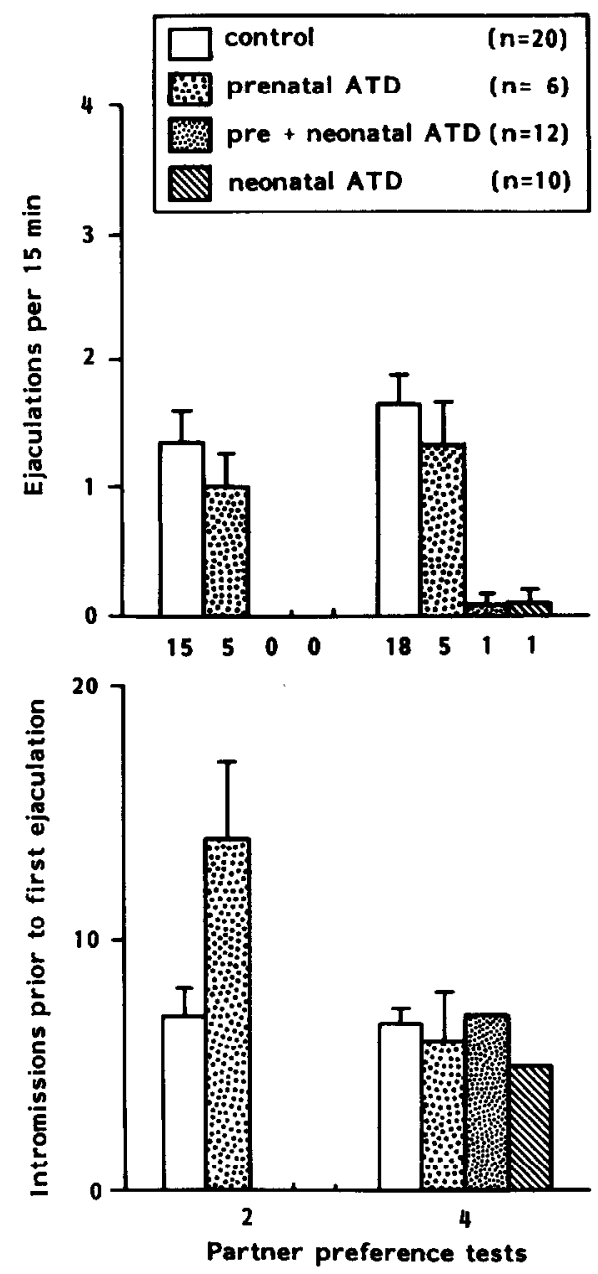

Fig. 2. (Top). Mean ( \pm SEM) ejaculation frequency of intact adult male rats during partner preference tests 2 and 4 as depicted in Fig. 1. The data of test 1 were not reliable and are therefore not presented; in test 3 sexual interaction was prevented by wire mesh. The digits below the bars represent the number of males per group that ejaculated during partner preference testing. (Bottom). Mean ( \pm SEM) number of intromissions prior to the first ejaculation of the males that ejaculated during partner preference testing (responders only).

$P<0.001)$ and $4\left(\chi^{2}=26.98, P<0.001\right)$ fewer group 1 males ejaculated than group 2 males, indicating that indeed neonatal ATD treatment lowered the number of males that ejaculated. Control males and pre-ATD males did not differ in ejaculation frequency in tests 2 and 4 (two-way ANOVA: groups $(F(1 / 24)=0.86$, ns), tests $(F(1 / 24)=1.66$; ns $)$, interaction $(F(1 / 24)=0.003, \mathrm{~ns}))$. 

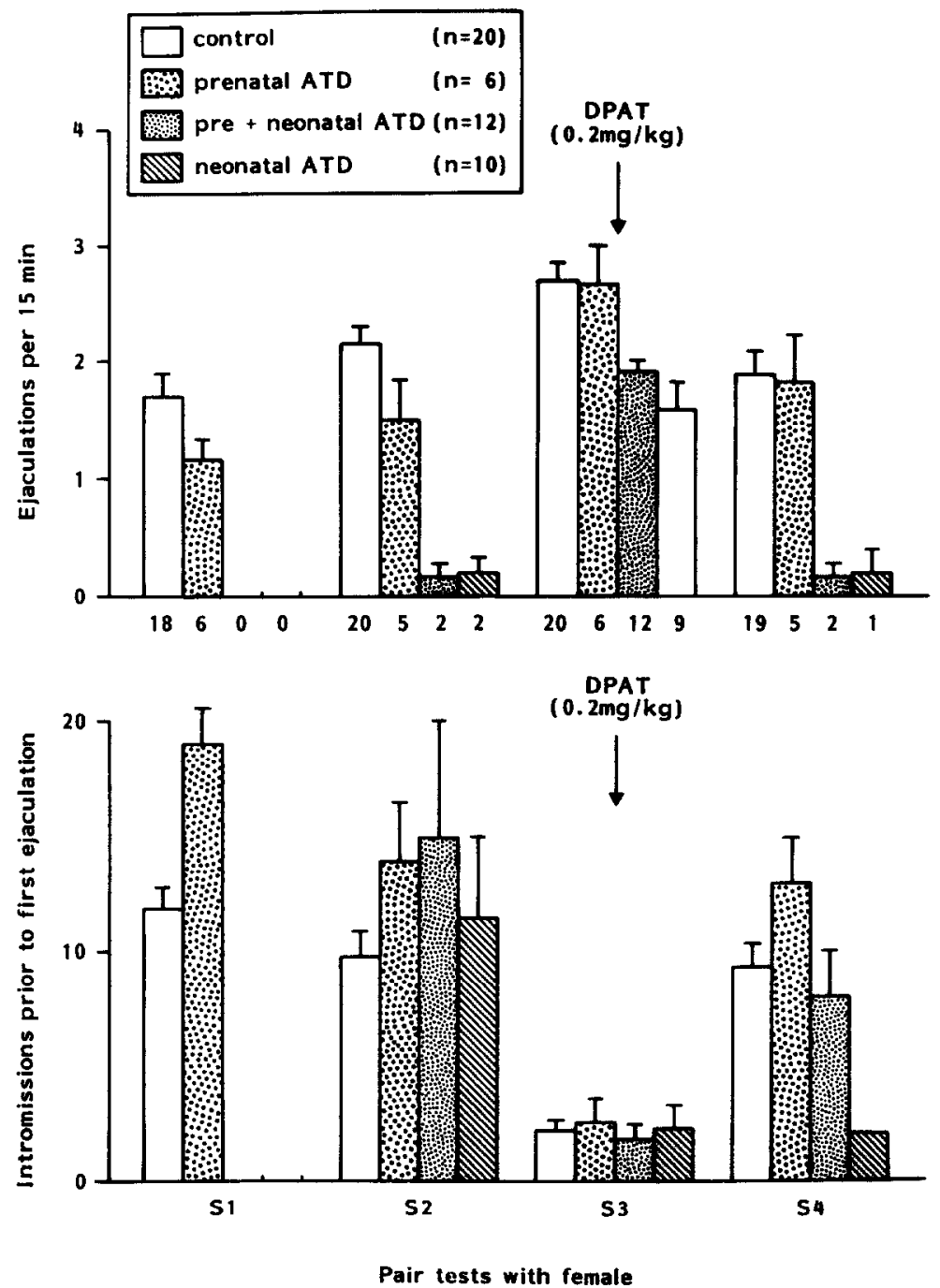

Fig. 3. (Top). Mean ( \pm SEM) ejaculation frequency of intact adult male rats during 15-min pair tests with an estrous female after perinatal ATD or control treatment. Tests were carried out in a semicircular arena. The digits below the bars indicate the number of males per group that ejaculated during pair testing. In test $\mathrm{S} 3$ the males were injected sc with $0.2 \mathrm{mg} / \mathrm{kg}$ 8-OH-DPAT $30 \mathrm{~min}$ prior to testing. (See text for details). (Bottom). Mean ( \pm SEM) number of intromissions prior to the first ejaculation of the males that ejaculated during pair testing (responders only). 


\begin{tabular}{|rr}
\hline control & $(n=20)$ \\
prenatal ATD & $(n=6)$ \\
preonatal ATD & $(n=10)$
\end{tabular}

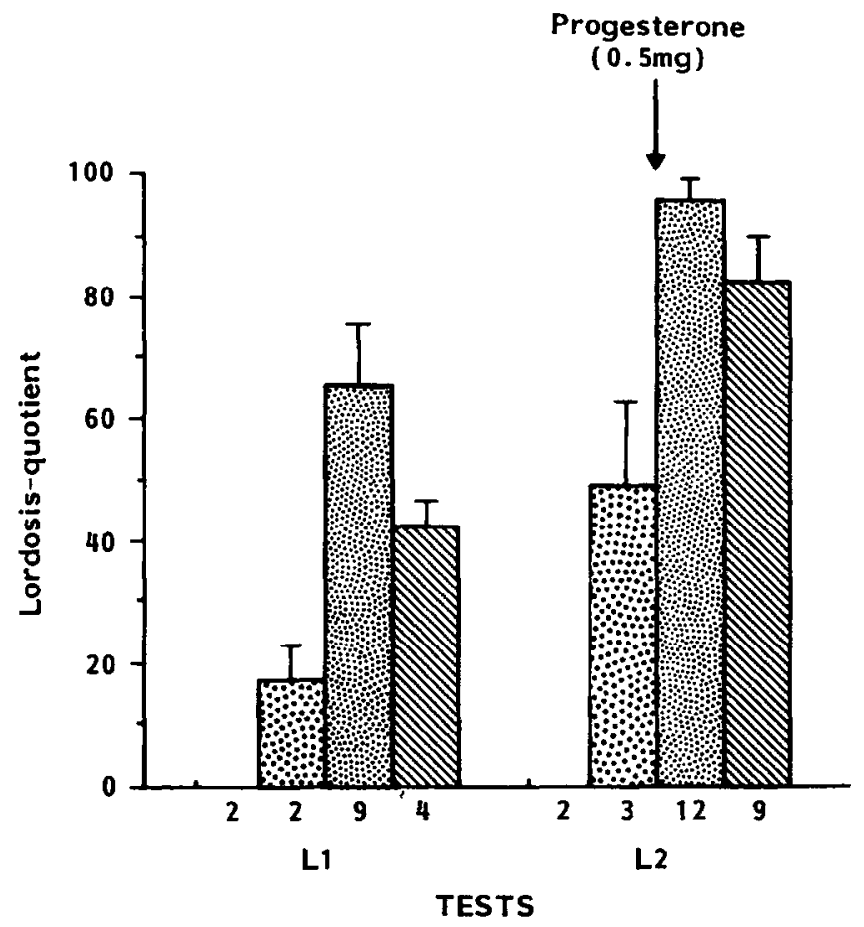

Fig. 4. Mean ( \pm SEM) lordosis quotients of intact adult male rats during pair tests with a sexually active male after perinatal ATD or control treatment. The digits below the bars indicate the number of males per group being mounted by the sexually active male three or more times. In test $\mathrm{L} 2$ the males were tested $4-7 \mathrm{hr}$ after a sc injection with 0.5 mg progesterone.

Sexual pair tests with estrous female. The ejaculation data of the four pair tests with an estrous female are shown in Fig. 3. The non-DPAT test data $(\mathrm{S} 1, \mathrm{~S} 2, \mathrm{~S} 4)$ were analyzed separately from the DPAT test data (S3). Two groups were formed for statistical analysis: group 1, with neonatal ATD, group 2, without neonatal ATD. Without DPAT more group 2 males (i.e., without neonatal ATD) than group 1 (i.e., with neonatal ATD) males ejaculated ( $1, \chi^{2}=37.00 ; S 2, \chi^{2}=27.12 ; \mathrm{S} 4, \chi^{2}=26.86$; all three $P<0.001$ ). Two-way ANOVA on ejaculation behavior showed that pre-ATD males ejaculated somewhat less than controls $(F(1 / 24)=$ $3.51 ; P<0.07)$. There was no significant effect of tests $(F(2 / 48)=2.04$; 
TABLE 1

\begin{tabular}{lc}
$\begin{array}{l}\text { Endogenous Serum Testosterone } \\
\text { (Mean } \pm \text { SEM) in Gonadally Intact }\end{array}$ \\
$\begin{array}{l}\text { Adult Male } \\
\text { Rats after Perinatal ATD Treatment }\end{array}$ \\
\hline Treatment & $\begin{array}{c}\text { T level } \\
(\mathrm{ng} / \mathrm{ml})\end{array}$ \\
\hline Control & $2.4 \pm 0.4$ \\
Prenatal ATD & $2.2 \pm 0.3$ \\
Pre- and neonatal ATD & $2.2 \pm 0.4$ \\
Neonatal ATD & $2.4 \pm 0.4$ \\
\hline
\end{tabular}

ns) and no interaction $(F(2 / 48)=0.72$, ns). DPAT stimulated ejaculation frequency in all males (test S3). One-way ANOVA of the ejaculation frequency showed an overall significant difference between groups $(F(3 / 44)=7.89 ; P<0.0005)$. Further analysis $(\operatorname{LSD}(5 \%)=0.56$ ejac $)$ revealed that the neo- and preneo-ATD males still had ejaculation frequencies lower than those of controls and pre-ATD males.

As can be seen in Fig. 3 (bottom) DPAT treatment decreased significantly the number of intromissions prior to the first ejaculation in all groups.

Lordosis behavior with active male. Lordosis data are shown in Fig. 4. Significantly more preneo-ATD control males were mounted by the sexually active male in test $\mathrm{L} 1\left(\chi^{2}=11.31, P<0.001\right)$ and $\mathrm{L} 2\left(\chi^{2}=21.16\right.$, $P<0.001$ ). In test L2 (after progesterone $4-7 \mathrm{hr}$ before testing) also more neo-ATD males $\left(\chi^{2}=15.09, P=0.0001\right)$ were mounted than controls. Lordosis quotients (one-way ANOVA) in test L1 showed a significant group difference $(F(3 / 13)=3.83 ; P<0.04)$. Further LSD $(5 \%)=42.0$ analysis showed that preneo-ATD males had higher lordosis quotients than control and pre-ATD males. In test $\mathbf{L} 2$ there was also a significant group difference $(F(3 / 22)=10.08 ; P<0.001)$. Further $\operatorname{LSD}(5 \%)=40.3$ analysis revealed that ATD-treated males showed significantly higher LQs than controls. The difference between preneo-ATD and pre-ATD males approached significance.

Hormone data. The mean levels of testosterone at 14.5 weeks of age can be seen in Table 1. One-way ANOVA showed no significant group differences $(F(3 / 41)=0.31, \mathrm{~ns})$. From these data it appears that perinatal ATD treatment had no effect on endogenous testosterone levels in these gonadally intact adult male rats.

\section{EXPERIMENT 2}

In the previous experiment the experimental males could interact behaviorally with the stimulus animals. Through this interaction and subsequent behavioral experience the preference behavior could be affected. 
Therefore a new experiment was carried out in which adult partner preference behavior was studied when interaction with the stimulus animals was initially prevented by wire mesh.

\section{Method}

Three groups of males were formed: (1) control $(n=14$; out of four litters); (2) prenatal ATD (pre-ATD; $n=12$; four litters); pre- and neonatal ATD (preneo-ATD; $n=18$; six litters).

As adults, from 11 weeks onward, the males were subjected to 13 weekly partner preference tests in the three-compartment box. In tests 1-7 wire mesh prevented sexual interaction. In tests 8-13 sexual interaction with the tethered incentives was possible. In tests 6,10 , and 12, 8-OH-DPAT was sc injected $30 \mathrm{~min}$ before testing $(0.2 \mathrm{mg} / \mathrm{kg}$ in tests 6 and $10 ; 0.4$ $\mathrm{mg} / \mathrm{kg}$ in test 12$)$. In tests $4,5,9,11$, and 13 saline $(2 \mathrm{ml} / \mathrm{kg})$ was injected 30 min before testing. In fact, tests 5 and 6 were carried out in a crossover design. The saline data are presented as test 5 and the DPAT data as test 6.

One and 2 weeks following the last partner preference test the males were pair tested with a sexually active male and with an estrous female.

\section{Results}

Partner preferences. Mean partner preference scores are shown in Fig. 5. Two-way ANOVA of tests 1-7 revealed a significant group difference $(F(2 / 41)=18.67, P<0.0005)$, a significant effect of tests $(F(6 / 246)=$ $15.76, P<0.0005)$, and no significant interaction $(12 / 246)=1.12$, ns). Further analysis of the group difference $(\operatorname{LSD}(5 \%)=70.7 \mathrm{sec})$ revealed that preneo-ATD males had significantly lower preference scores than pre-ATD and control males; the latter two groups did not differ. Further analysis of the effect of tests $(\operatorname{LSD}(5 \%)=72.6 \mathrm{sec})$ showed overall gradually increasing preference scores for the estrous female (test 1 , overall mean: $-24 \mathrm{sec}$, test $7: 304 \mathrm{sec}$ ). The differences were significant between tests 1 and 2,2 and 4, as well as between 6 and 7. 8-OH-DPAT given in test 6 did not significantly affect partner preference.

It is of interest that in test 1 most control males (10 out of 14), half of the pre-ATD males (6 out of 12), and only a few preneo-ATD males (5 out of 18 ) preferred the estrous female. In test 7 nearly all males preferred the estrous female.

Two-way ANOVA on data of tests 8-13 revealed a significant group difference $(F(2 / 41)=119.51, P<0.0005)$, a significant effect of tests $(F(2 /$ $205)=17.70, P<0.0005)$, and no significant interaction $(F(10 / 205)=$ $0.64, \mathrm{~ns})$. Further analysis of the group difference $(\operatorname{LSD}(5 \%)=66.1 \mathrm{sec})$ showed that preneo-ATD males had lower preference scores than preATD and control males; the latter two groups did not differ. Further analysis of the effect of tests $(\operatorname{LSD}(5 \%)=92.7 \mathrm{sec})$ showed overall 


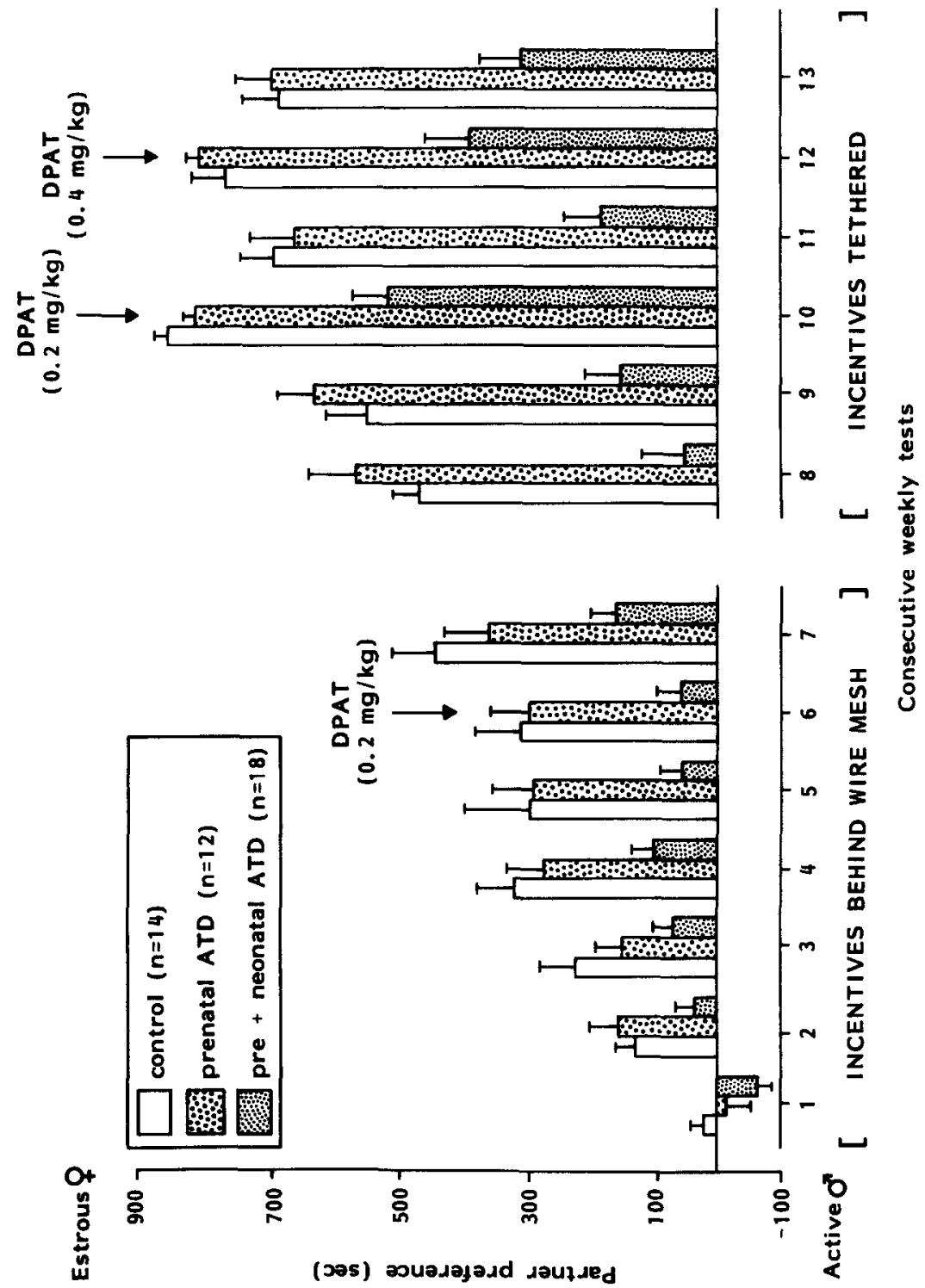


increasing preference scores for the estrous female (test 8, overall mean: $325 \mathrm{sec}$; test 13: $536 \mathrm{sec}$ ) with two peaks, namely test 10 (overall: 706 $\mathrm{sec})$ and $12(624 \mathrm{sec})$, coinciding with the 8-OH-DPAT treatment.

Sexual behavior with tethered estrous female. The sexual interaction data obtained during partner preference tests 8-13 are shown in Fig. 6. Tests without DPAT treatment $(8,9,11,13)$ were analyzed separately from tests with DPAT $(10,12)$. Since only a few preneo-ATD males ejaculated in tests without DPAT, a $\chi^{2}$ analysis was carried out on the number of males ejaculating. This showed that more controls $\left(\chi^{2}=22.7, P<0.001\right)$ and pre-ATD males $\left(\chi^{2}=16.4, P<0.001\right)$ ejaculated than preneo-ATD males.

Comparing control and pre-ATD males during the non-DPAT tests (2way ANOVA), revealed a significant overall difference between groups $(F(1 / 24)=15.20, P=0.001)$, a significant cffect of tests $(F(3 / 72)=$ $7.22, P<0.0005)$, and no significant interaction $(F(3 / 72)=0.77$, ns). Further analysis of the effect of tests $(\operatorname{LSD}(5 \%)=0.54$ ejacs) showed an increasing number of ejaculations per test, reaching significance between tests 8 and 9 , as well as between 9 and 11 . Controls ejaculated more often than pre-ATD males.

Analysis of DPAT tests 10 and 12 revealed a significant group difference (2-way ANOVA; $F(2 / 41)=7.82, P=0.001$ ), a significant effect of tests $(F(1 / 41)=29.97, P<0.0005)$, and no significant interaction $(F(2 / 41)=$ 1.60 , ns). Further analysis of the group difference $(\operatorname{LSD}(5 \%)=0.58$ ejacs) showed that with DPAT treatment controls ejaculated significantly more than pre- and preneo-ATD males; the last two groups did not differ. The ejaculation frequency was significantly higher in test 12 than in test 10. As can be seen in Fig. 6, DPAT treatment significantly increased the number of males ejaculating, especially in the preneo-ATD group.

The number of intromissions prior to the first ejaculation was decreased by 8-OH-DPAT treatment. This treatment resulted sometimes in "premature ejaculation," i.e., ejaculation during the first intromission: with low dose $(0.2 \mathrm{mg} / \mathrm{kg})$ DPAT in $21 \%$ of males $(8 / 38$ ejaculators), with high dose $(0.4 \mathrm{mg} / \mathrm{kg})$ in $81 \%$ of males $(35 / 43$ ejaculators).

Sexual pair tests with estrous female and with active male. The results are depicted in Fig. 7. Fewer preneo-ATD males ejaculated than pre-

FIG. 5. Mean ( \pm SEM) preference (seconds) for an estrous female over a sexually active male of intact adult male rats after perinatal ATD or control treatment. They received 13 weekly tests for partner preference behavior using the three-compartment box. In tests 17 sexual interaction with the incentives, an estrous female and a sexually active male, was prevented by wire mesh; in tests 8-13 sexual interaction with the tethered incentives was possible. The preference scores were calculated as described in the legend to Fig. 1. In tests 6 , 7, and 12 the experimental males were injected sc with 8-OH-DPAT (30 min prior to testing) in dosages indicated in the figure. 


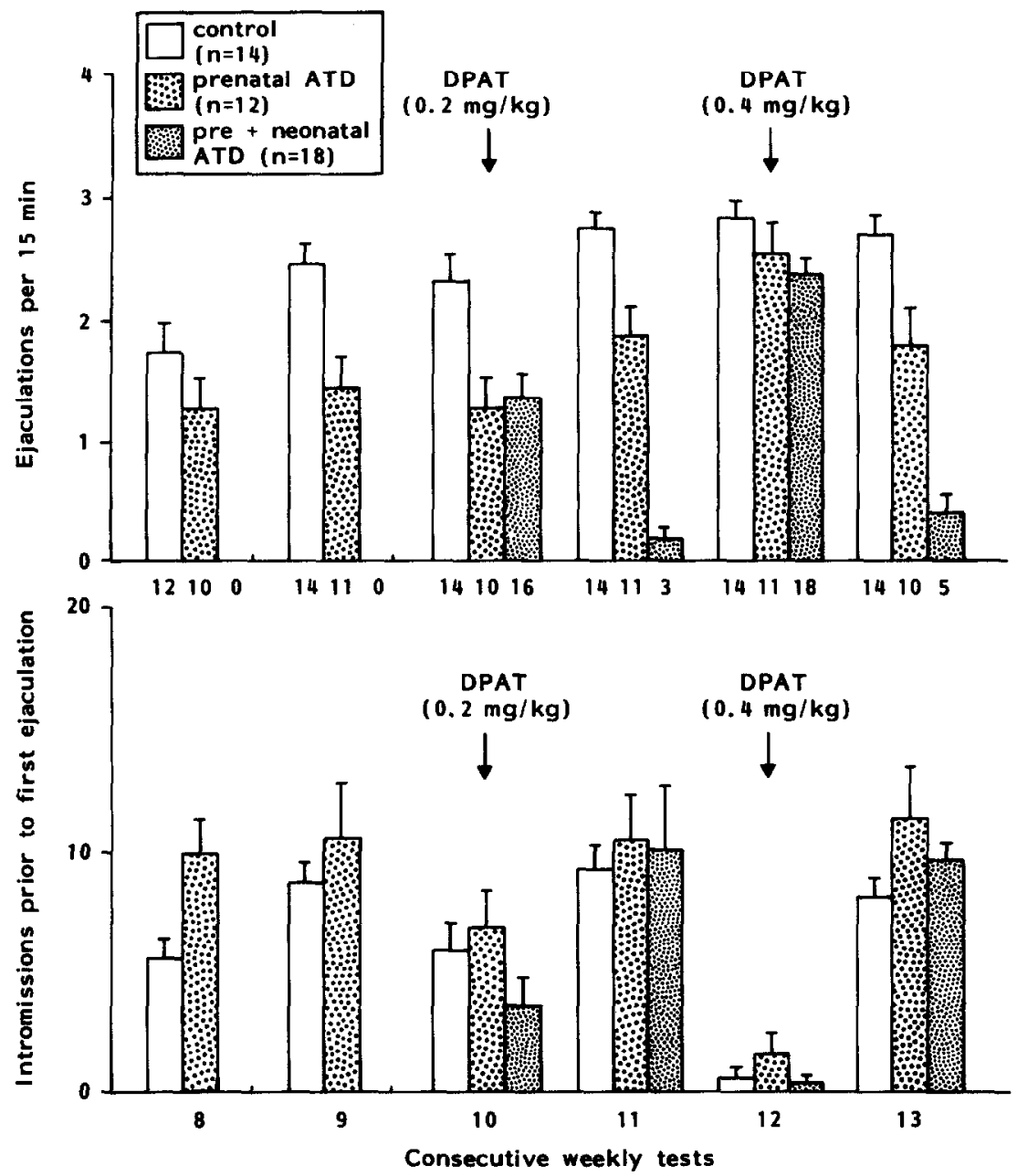

Fig. 6. (Top). Mean ( \pm SEM) ejaculation frequency during partner preference tests 8-13 (see Fig. 5) of intact adult male rats after perinatal ATD or control treatment. The digits below the bars indicate the number of males per group that ejaculated during partner preference testing. In tests 10 and 12 the males were injected sc with 8-OH-DPAT (30 min prior to testing) in dosages of 0.2 and $0.4 \mathrm{mg} / \mathrm{kg}$, respectively. (Bottom). Mean ( \pm SEM) number of intromissions prior to the first ejaculation of the males that ejaculated during partner preference testing (responders only).

ATD males $\left(\chi^{2}=10.46, P=0.001\right)$ and controls $\left(\chi^{2}=15.37, P<\right.$ $0.0001)$. The number of males ejaculating in the pre-ATD and control group did not differ $\left(\chi^{2}=0.02\right.$, ns). One-way ANOVA of the mean ejaculation frequencies of the control and pre-ATD males showed a significant group difference $(F(1 / 24)=6.54, P<0.02)$. In fact, controls 

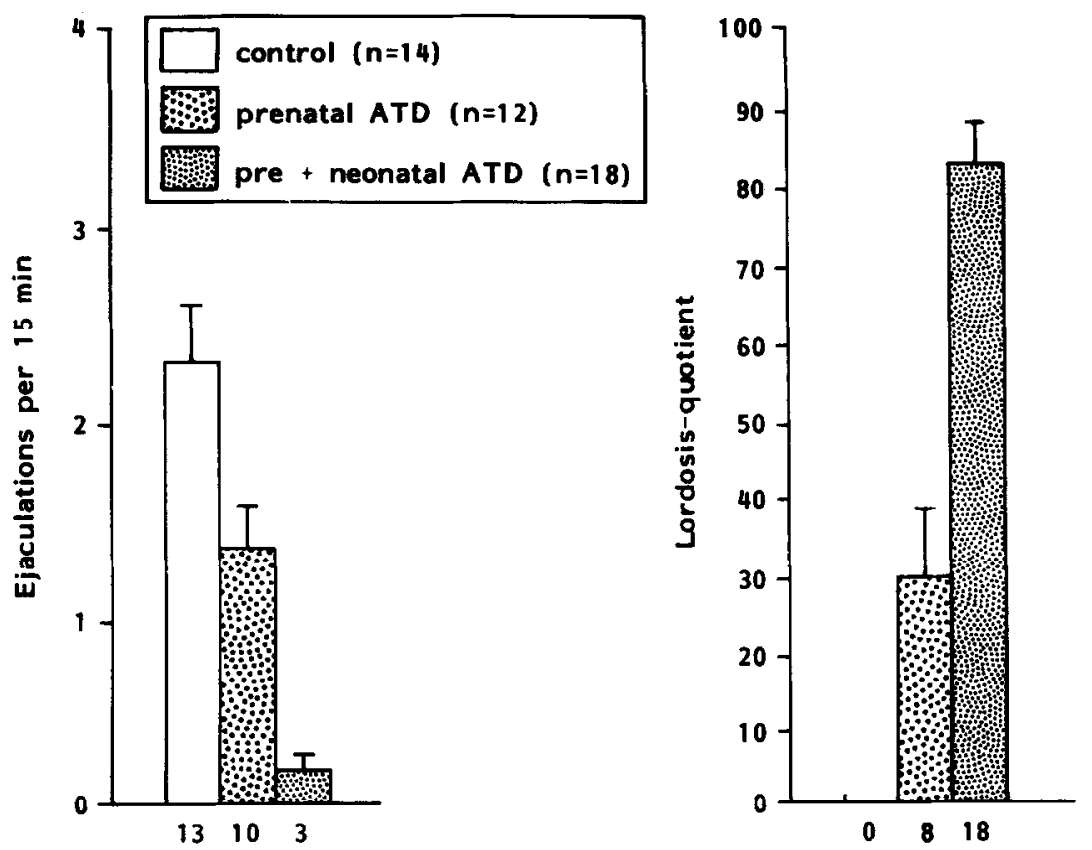

Fig. 7. (Left). Mean ( \pm SEM) ejaculation frequency during a 15-min pair test with an estrous female in a semicircular arena of the same males as in Fig. 6 . The digits below the bars indicate the number of males per group that ejaculated during the pair test. (Right). Mean ( \pm SEM) lordosis quotient during a pair test with a sexually active male of the same males as the left hand panel. The males were still intact and did not receive any exogenous steroids. The numbers below the bars indicate the number of males per group being mounted three or more times by the sexually active male.

ejaculated more often than pre-ATD males. Looking at lordosis behavior (right hand panel) it appeared that more preneo-ATD males were mounted by the stud male than pre-ATD males $\left(\chi^{2}=4.34, P<0.04\right)$ and than controls $\left(\chi^{2}=28.07, P<0.001\right)$. The pre-ATD males were also more readily mounted than the control males $\left(\chi^{2}=10.53, P<\right.$ $0.002)$. One-way ANOVA of the lordosis quotients $(F(1 / 24)=29.22$, $P<0.005)$ showed that preneo-ATD males had higher LQs than preATD males.

\section{DISCUSSION}

This study, carried out with intact male rats, clearly shows that adult partner preference behavior can be added to the list of behaviors in the male rat that are (at least partially) "organized" during a critical period. It seems that testosterone through its estradiol metabolite is responsible for this programming. The critical period seems to be mainly (early) neonatal, since prenatal ATD treatment only slightly affected partner 
preference. The main results of the present experiments corroborate earlier findings from our lab (Brand and Slob, 1991), but are not in line with data reported by Davis et al. (1979). The latter authors could not find changes in adult partner preference following ATD treatment during postnatal Days 2-10. It is suggested that Davis et al. started their ATD treatment (Postnatal Day 2) too late. In the present experiments ATD treatment was started on Day 1, when high levels of testosterone are circulating (e.g., Baum et al., 1988).

Neonatal ATD administration impairs the ability of most males to ejaculate. Prenatal ATD was able to lower the ejaculation frequency in one experiment (experiment 2), but not in the other (experiment 1). The route of administration may be relevant in this respect, presumably higher blood levels of ATD were achieved after sc injection to the mother (experiment 2) than following treatment with a silastic implant placed sc in the back (experiment 1).

The ejaculation data of the neo-ATD males are not in line with those of Vreeburg et al. (1977) and Davis et al. (1979). Vreeburg et al. reported that males injected with $1 \mathrm{mg}$ ATD on the day of birth (Day 1) and on Days $3,5,10$, and 15 postnatally, showed normal male copulatory behavior in adulthood. The discrepancy between our results, i.e., a loss of the ejaculation capacity, and the normal ejaculation response reported by Vreeburg et al. (1977) may be due to the treatment regimen. The latter investigators injected ATD with intervals of at least 2 days between injections. We used a silastic implant that continuously released ATD. Davis et al. (1979) used male rats treated with a 5-mm long Silastic implant containing ATD (controls received an empty implant) on Days 2-10. Tested as adults (about 90 days of age) there were no differences in the ejaculation behavior of 14 ATD and 12 control males. As discussed earlier for partner preference behavior, the difference in the time of onset of treatment may account for the difference with our findings; i.e., Davis $e t$ al. (1979) started their ATD treatment too late. The results of Booth (1978) are in line with the present experiments. She castrated male rats at birth and treated them with an aromatase inhibitor ADT in combination with T. Masculinization was suppressed, such that none of the ADT + $\mathrm{T}$ treated rats ejaculated in adulthood. This suggests that estradiol plays an important role in the organization of this behavior.

The ejaculation data of the pre-ATD males in the present study are ambiguous: in experiment 1 no effect was found, in experiment 2 the ejaculation frequency was lowered. We have suggested above that the route of ATD administration (Silastic implant vs sc injection) may be relevant in this regard. However, ambiguous results have also been published by Gladue and Clemens (1980) and Whalen and Olsen (1981) who both used prenatal injections to the mother as the manner of ATD administration. Whalen and Olsen found no significant effects, whereas 
Gladue and Olsen found a slightly lower percentage of animals ejaculating in the $5 \mathrm{mg}$ ATD group.

Perinatal ATD treatment and in some tests also prenatal ATD treatment rendered males to be more attractive than controls; i.e., they were more readily mounted by the stud male. This corroborates data from de Jonge and Meyerson (1982) who reported that neonatally castrated males were more approached by male rats than intact males in a choice apparatus. Thus, the lack of endogenous gonadal hormones neonatally rendered such males to be (more) attractive to normal males. In the present study, preneo-ATD males were hardly defeminized since they showed high lordosis quotients. Pre-ATD males were somewhat defeminized, more so than preneo-ATD males, but less than control males. It should be kept in mind that in the present experiments all adult males were gonadally intact and did not receive any exogenous steroids.

It is known from the literature that male rats perinatally treated with ATD, castrated in adulthood and treated with EB with or without $P$, show high levels of lordosis behavior (Vreeburg et al., 1977; McEwen et al., 1977; Clemens and Gladue, 1978; Fadem and Barfield, 1981; Whalen et al. 1986). Davis et al. (1979) reported increased lordosis quotients in gonadally intact adult male rats which were neonatally treated with ATD. From our data we conclude that ATD treatment at least partially prevents the defeminization of intact males. Neonatal ATD treatment seems to have more effect than prenatal ATD treatment. This suggests that the defeminization of the male rat occurs mainly neonatally, presumably through the estradiol metabolite of testosterone.

The facilitatory effects of progesterone for lordosis behavior in our ATD treated intact male rats is in line with other studies (e.g., van de Poll and van Dis, 1977). In the latter study intact males showed higher lordosis quotients than adult castrated males following adult estrogen plus progesterone treatment. The fact that our control males did not show lordosis behavior could be due to a lack of sufficient levels of endogenous estradiol, since estradiol treatment stimulates lordosis behavior in intact male rats (van de Poll and van Dis, 1977). It could be hypothesized that ATD-treated males in the present study had higher endogenous $E_{2}$ levels and/or their CNS is more sensitive to $E_{2}$. However, higher $E_{2}$ levels and/or a more $E_{2}$-sensitive $C N S$ are at variance with a decrease in female partner preference, since estradiol treatment stimulates preference for an estrous female vs an active male (Meyerson, Eliasson, and Hetta, 1979). Further research is needed to elucidate these possibilities.

8-OH-DPAT, a known stimulator of male rat sexual behavior (e.g., Ahlenius et al., 1981), increased the preference scores for an estrous female in all groups when sexual interaction was possible (experiment 2). It was, however, unable to totally undo the effect of neonatal ATD. DPAT was able to increase the number of males that ejaculated in the 
preneo-ATD male group. DPAT lowered the number of intromissions preceding the first ejaculation. This resulted quite often in premature ejaculation, i.e., ejaculation with the first intromission. This phenomenon occurred in about $20 \%$ of the males with low dose DPAT and in about $80 \%$ with high dose DPAT, regardless of perinatal treatment. DPAT treatment has no lasting effects on partner preference behavior and on male sexual behavior: tests 1 week after DPAT tests showed results similar to those of tests preceding DPAT. This indicates that the neonatal ATD effects cannot be overcome by one learning experience. This suggests that ATD has indeed permanently affected the CNS. Such males behave differently to the activating action of their own testicular hormones. Apparently, 8-OH-DPAT is able to bypass, in an unknown way, the affected CNS structures. Perhaps DPAT activated alternative CNS-networks that activate normal male sexual orientation and behavior.

In conclusion, the present data suggest that partner preference behavior of male rats is programmed neonatally, presumably by estradiol derived from endogenous testosterone. A lack of neonatal estrogen impairs adult ejaculatory behavior (such males are less masculinized) and enhances lordosis behavior in intact male rats (they are less defeminized). Treatment with 8-OH-DPAT (a serotonin agonist) abolishes most effects of perinatal ATD treatment on adult partner preference behavior as well as on ejaculatory behavior.

\section{ACKNOWLEDGMENTS}

The authors thank J. van Ophemert, S. Haensel, and M. Vollebregt for assistance in the collection of the data; M. P. Ooms for performing the testosterone RIA; and Dr. D. R. Rowland for statistical advice. The authors are indebted to Drs. J. J. van der Werff ten Bosch, F. H. de Jonge, and N. E. van de Poll for critical reading of an earlier version of the manuscript.

\section{REFERENCES}

Adkins-Regan, E. (1988). Sex hormones and sexual orientation in animals. Psychobiology 16, 335-347.

Ahlenius, S., Larsson, K., Svensson, L., Hjorth, S., Carlsson, A., Lindherg, P., Wikström, H., Sanchez, D., Arvidsson, L.-E., Hacksell, U., and Nilsson, J. L. G. (1981). Effects of a new type of 5-HT receptor agonist on male rat sexual behavior. Pharmacol. Biochem. Behav. 15, 785-792.

Baum, M. J. (1979). Differentiation of coital behavior in mammals: A comparative analysis. Neurosci. Biobehav. Rev. 3, 265-284.

Baum, M. J., Brand, T., Ooms, M., Vreeburg, J. T. M., and Slob, A. K. (1988). Immediate postnatal rise in whole body androgen content in male rats: Correlation with increased testicular content and reduced body clearance of testosterone. Biol. Reprod. 38, 980986.

Booth, J. E. (1978). Effects of the aromatization inhibitor androst-4-ene-3,6,17-trione on sexual differentiation induced by testosterone in the neonatally castrated rat. $J$. Endrocr. 79, 69-76. 
Brand, T., and Slob, A. K. (1991). Neonatal organization of adult partner preference behavior in male rats. Physiol. Behav. 49, 107-111.

Clemens, L. G., and Gladue, B. A. (1978). Feminine sexual behavior in rats enhanced by prenatal inhibition of androgen aromatization. Horm. Behav. 11, 190-201.

Davis, P. G., Chaptal, C. V., and McEwen, B. S. (1979). Independence of the differentiation of masculine and feminine sexual behavior in rats. Horm. Behav. 12, 12-19.

De Jonge, F. H., and Meyerson, B. J. (1982). Attractivity of male and female rats after early endocrine manipulation. Horm. Behav. 16, 1-12.

Edwards, D. A., and Pfeifle, J. K. (1983). Hormonal control of receptivity, proceptivity, and sexual motivation. Physiol. Behav. 30, 437-443.

Fadem, B. H., and Barfield, R. J. (1981). Neonatal hormonal influences on the development of proceptive and receptive feminine sexual behavior in rats. Horm. Behav. 15, 282288.

Gladue, B. A., and Clemens, L. G. (1980). Masculinization diminished by disruption of prenatal estrogen biosynthesis in male rats. Physiol. Behav. 25, 589-593.

Kaplan, M. E., and McGinnis, M. Y. (1989). Effects of ATD on masculine sexual behavior and androgen receptor binding: $\mathrm{A}$ reexamination of the aromatization hypothesis. Horm. Behav. 23, 10-26.

Kirk, R. E. (1968). Experimental Design: Procedures for the Behavioral Sciences. Brooks/Cole, Belmont, CA.

McEwen, B. S., Lieberburg, I., Chaptal, C., and Krey, L. C. (1977). Aromatization: Important for sexual differentiation of the neonatal rat brain. Horm. Behav. 9, 249263.

Meyerson, B. J., Eliasson, M., and Hetta, J. (1979). Sex-specific orientation in female and male rats: Development and effects of early endocrine manipulation. In A. M. Kaye and M. Kaye (Eds.), Development of responsiveness to Steroid Hormones: Advances in the Biosciences, Vol. 25, pp. 451-460. Pergamon, Oxford.

Perlman, G. (1986). The UNIX/STAT Handbook: Data Analysis Programs on UNIX and $M S D O S$. Wang Institute, Tyngsboro.

Slob, A. K., De Klerk, L. W. L., and Brand, T. (1987). Homosexual and heterosexual partner preference in ovariectomized female rats: Effects of testosterone, estradiol and mating experience. Physiol. Behav. 41, 571-576.

van de Poll, N. F., and van Dis, H. (1977). Hormone-induced lordosis and its relation to masculine sexual activity in male rats. Horm. Behav. 8, 1-7.

Vreeburg, J. T. M., van der Vaart, P. D. M., and van der Schoot, P. (1977). Prevention of central defeminization but not masculinization in male rats by inhibition neonatally of oestrogen biosynthesis. J. Endocr. 74, 375-382.

Whalen, R. E., Gladue, B. A., and Olsen, K. L. (1986). Lordotic behavior in male rats: Genetic and hormonal regulation of sexual differentiation. Horm. Behav. 20, 73-82.

Whalen, R. E., and Olsen, K. L. (1981). Role of aromatization in sexual differentiation: Effects of prenatal ATD treatment and neonatal castration. Horm. Behav. 15, 107122. 